\title{
Effect of Calcium Antagonists on Vascular Responses of Bovine Coronary Artery to Acetylcholine, Noradrenaline, and 5-Hydroxytryptamine
}

\author{
Fadhil A. WALI* and Erskine GreENIDGE** \\ *Anaesthetics Unit, and ${ }^{* *}$ Department of Physiology, \\ The London Hospital Medical College, \\ Whitechapel, London E1 1BB, U.K.
}

\begin{abstract}
Summary Verapamil $(0.05-5 \mu \mathrm{M})$, diltiazem $(0.2-20 \mu \mathrm{M})$, and nifedipine $(0.3-30 \mu \mathrm{M})$ produced concentration-dependent relaxation of bovine coronary artery. Based on the $\mathrm{EC}_{50}$ values (concentration to produce $50 \%$ maximum response), the calcium entry blocker verapamil (relative potency $=1$ ) was 3.4 and 7 times as potent as diltiazem and nifedipine, respectively, in producing relaxation of bovine coronary artery. In addition, verapamil reduced the contractions produced by acetylcholine $(0.01-10 \mu \mathrm{M})$, 5-hydroxytryptamine $(5-\mathrm{HT})(0.01-10 \mu \mathrm{M})$ whereas it potentiated the relaxation produced by noradrenaline $(0.01-10 \mu \mathrm{M})$. It was concluded that verapamil, diltiazem, and nifedipine (a) relax the bovine coronary artery, verapamil being more potent than diltiazem and nifedipine, and (b) the calcium entry blockers modified the contractile responses to neurotransmitter agents, acetylcholine, noradrenaline, and 5HT, inhibiting the contractions produced by acetylcholine and 5-HT, and enhancing the relaxation produced by noradrenaline.
\end{abstract}

Key words: calcium antagonists, neurotransmitters, bovine coronary artery.

The effects of calcium entry blockers on the cardiovascular system are wellknown, in that they inhibit myocardial excitation-contraction coupling and dilate peripheral blood vessels. However, recent reports in the literature have indicated that calcium entry blockers may differ in their effects on the cardoivascular system, in duration of action and tissue selectivity (SpEDDING, 1985; DeFEudis, 1985).

In the present investigation, the effects of 3 different calcium entry blockers, verapamil, diltiazem, and nifedipine, on tone and contractility of bovine coronary

Received for publication February 10, 1986

* To whom all correspondence should be addressed. 
artery were studied to see if the calcium entry blockers differ in their effects on tone and contractility of coronary artery in vitro.

The coronary artery, a part of the anterior descending branch of the left coronary artery, $4-5 \mathrm{~mm}$ diameter, was obtained from cattle hearts within $20 \mathrm{~min}$ of slaughter (killed by exsanguination). The artery was transported to the laboratory in chilled $\left(0-5^{\circ} \mathrm{C}\right)$ standard saline solution. The adventitia was removed from the arteries which were then cut into helical strips, 2-3 mm wide and $20-30 \mathrm{~mm}$ long (CAMPBell et al., 1983; DoChERTY and Hyland, 1985). Strips of coronary artery were cut from the anterior descending branch $50-80 \mathrm{~mm}$ distal to its origin. In the present experiments, the endothelium was lost during the preparation of the strips, and by mechanical rubbing of the tissue. In the absence of endothelium, acetylcholine $(\mathrm{ACh})$, and other neurotransmitters produce contraction of arteries (FURCHGOTT, 1981).

The preparation was set up, under a tension of $0.5 \mathrm{~g}$, in an organ bath containing $20 \mathrm{ml}$ of Krebs-Henseleit solution maintained at $38 \pm 2 \mathrm{C}$ and bubbled with $5 \% \mathrm{CO}_{2}$ in $\mathrm{O}_{2}$. The final $\mathrm{pH}$ of the $\mathrm{Krebs}$ solution was adjusted to 7.2. The composition of the $\mathrm{Krebs}$ solution was (mM): $\mathrm{NaCl} 118, \mathrm{KCl} 4.75, \mathrm{CaCl}_{2} \cdot 6 \mathrm{H}_{2} \mathrm{O}$ 2.54, $\mathrm{KH}_{2} \mathrm{PO}_{4}$ 1.2, $\mathrm{MgSO}_{4} 1.2, \mathrm{NaHCO}_{3} 25$, and glucose 11.1. After the preparation was set up, it was left in the bath for about $15 \mathrm{~min}$ to settle before drug application. Mechanical responses (relaxation or contraction) induced by drug application were recorded isometrically using a force-displacement transducer (Dl $50 \mathrm{~g}$ ) and a Washington pen recorder (model $400 \mathrm{MD} 2 \mathrm{C}$, Bioscience, U.K.). The frequency-response of the amplifier of the recorder was linear up to $28 \pm 2 \mathrm{~Hz}$, declining to a minimum with $\mathrm{a}-3 \mathrm{~dB}$ of about $38 \mathrm{~Hz}$.

Concentration-response curves were constructed for each drug alone, and sometimes in the presence of another drug, and the mean $\mathrm{EC}_{50}$ values (i.e. concentration to produce $50 \%$ maximum contraction or relaxation) of druginduced responses were determined. In constructing the concentration-response curves, the cumulative method was not used, for fear of accumulation of drugs with time (Williams et al., 1983). The single concentration pattern was used, and individual concentrations were given in a random manner. Drugs were added into the bath containing the preparation, in small volumes, 0.2 or $0.4 \mathrm{ml}$, to give a final desired concentration, i.e. concentration at the muscle. Drugs were applied, for 4-5 min, until a maximum effect was obtained, and the preparation was washed out in control Krebs solution (2-3 times) to allow for the recovery of the responses. However, when high concentrations of calcium antagonists were used, recovery process was difficult and took a long time (20-30 min), depending on the concentration used. The effect of each drug on at least 3 fresh preparations (six strips) was studied. All drugs and solutions were made up in de-ionized distilled water. The drugs used were: verapamil $\mathrm{HCl}$ (Cordilox, Abbott), nifedipine (Adalat, Bayer), diltiazem HCl (Lorex LP 11956), ACh chloride (Sigma), noradrenaline (NA) L bitartrate (Koch-Light), 5-hydroxytryptamine (5-HT) creatinine sulphate (Sigma), atropine sulphate (Sigma), propranolol $\mathrm{HCl}$ (Sigma), yohimbine $\mathrm{HCl}$ (Sigma), 
Table 1. Effects of calcium entry blockers and neurotransmitters on tone and contractility of bovine coronary artery in vitro.

\begin{tabular}{lccccc}
\hline & $\begin{array}{c}\text { Maximum } \\
\text { response } \\
(\mathrm{g})\end{array}$ & $\begin{array}{c}\text { Control } \\
\mathrm{EC}_{50} \\
(\mu \mathrm{M})\end{array}$ & $\begin{array}{c}\mathrm{EC}_{50} \text { in } \\
\text { verapamil } \\
(\mu \mathrm{M})\end{array}$ & $\begin{array}{c}\mathrm{EC}_{50} \\
\text { ratio } \\
(\mathrm{V} / \mathrm{C})\end{array}$ & $\begin{array}{c}\% \text { Reduction } \\
\text { in maximum } \\
\text { response }\end{array}$ \\
\hline $\begin{array}{l}\text { Verapamil* } \\
(0.05-5 \mu \mathrm{M})\end{array}$ & $1.4 \pm 0.1$ & $0.9 \pm 0.2$ & - & - & - \\
$\begin{array}{l}\text { Diltiazem* } \\
(0.2-20 \mu \mathrm{M})\end{array}$ & $1.1 \pm 0.1$ & $3.1 \pm 0.1$ & - & - & - \\
$\begin{array}{l}\text { Nifedipine* } \\
(0.3-30 \mu \mathrm{M})\end{array}$ & $0.8 \pm 0.2$ & $6.3 \pm 0.1$ & - & - & - \\
$\begin{array}{l}\text { ACh* } \\
(0.01-10 \mu \mathrm{M})\end{array}$ & $1.5 \pm 0.1$ & $2.0 \pm 0.1$ & $3.0 \pm 0.1$ & $1.5: 1.0$ & $45 \pm 3 \%$ \\
$\begin{array}{l}\text { NA* } \\
(0.01-10 \mu \mathrm{M})\end{array}$ & $0.6 \pm 0.2$ & $4.0 \pm 0.2$ & $2.0 \pm 0.1$ & $0.5: 1.0$ & $38 \pm 2 \%$ \\
$5-\mathrm{HT} * *$ & $2.5 \pm 0.1$ & $0.8 \pm 0.2$ & $1.6 \pm 0.1$ & $2.0: 1.0$ & $40 \pm 1 \%$ \\
$(0.01-10 \mu \mathrm{M})$ & & & & & \\
\hline
\end{tabular}

All values are mean \pm S.E. ${ }^{*}$ Relaxation, ${ }^{* *}$ contraction.

prazosin $\mathrm{HCl}$ (Pfizer), ketanserin tartrate (Janssen), methysergide bimaleate (Sandoz), and potassium chloride (Sigma). The nifedipine solution was freshly prepared daily in polyethylene glycol:ether:water $(15: 15: 50, \mathrm{~V}: \mathrm{V}: \mathrm{V})$. The vehicle used had no significant effect on the coronary artery. The nifedipine solution was protected from direct light source and all experiments were done in darkness (CHEung, 1985a, b). Mean \pm S.E. of values were calculated and a Student's $t$-test was employed to test the significance between two sets of paired observations in the same experiment. To evaluate the difference between the concentration-response curves, the analysis of variance was used. A probability value of $p<0.05$ was considered significant.

Verapamil $(0.05-5 \mu \mathrm{M})$, diltiazem $(0.2-20 \mu \mathrm{M})$, and nifedipine $(0.3-30 \mu \mathrm{M})$ relaxed the bovine coronary artery in the presence of propranolol $(1 \mu \mathrm{M})$, to block $\beta$ adrenergic influences. The mean maximum relaxations and the $\mathrm{EC}_{50}$ values (concentration to produce $50 \%$ maximum response) of calcium entry blockerinduced relaxation are shown in Table 1 . Based on the $\mathrm{EC}_{50}$ values, verapamil (relative potency $=1$ ) was about 3.4 and 7 times as potent as diltiazem and nifedipine, respectively, in relaxing the bovine coronary artery. As mentioned earlier, the coronary artery strips did not contain endothelium, and thus there was no obvious protection against vasocontrictor effects of drugs. ACh $(0.01-10 \mu \mathrm{M})$ and 5-HT $(0.01-10 \mu \mathrm{M})$ contracted whereas NA $(0.01-10 \mu \mathrm{M})$ relaxed the bovine coronary artery. The mean maximum contraction or relaxation and the mean $\mathrm{EC}_{50}$ values of ACh, NA, and 5-HT-induced responses are shown in Table 1. Based on the $\mathrm{EC}_{50}$ values, $5-\mathrm{HT}$ was twice as potent as $\mathrm{ACh}$, in contracting the coronary 


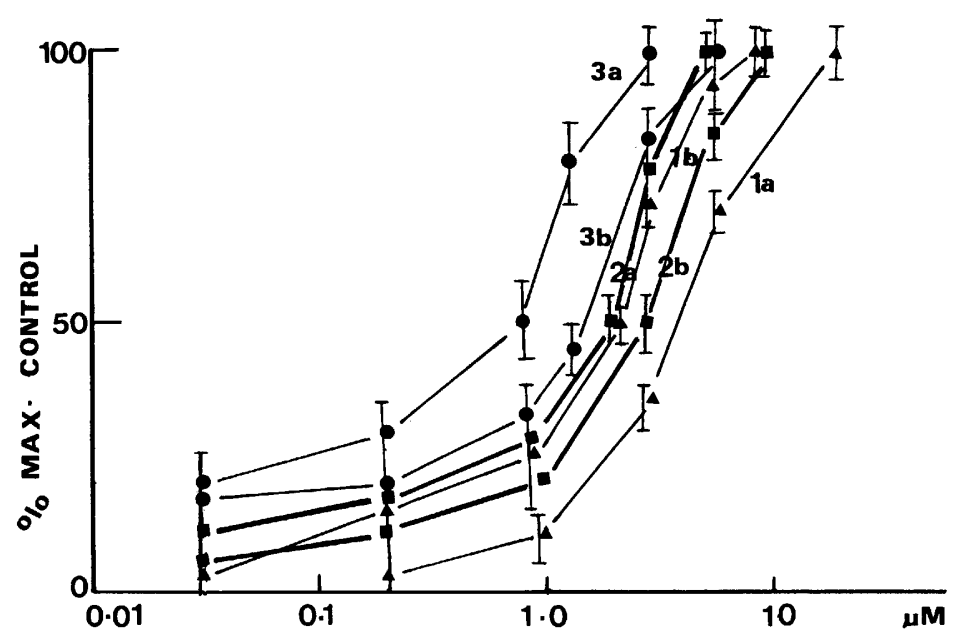

Fig. 1. Log. dose-response curves for the effects of noradrenaline, acetylcholine (ACh), and 5-hydroxytryptamine (5-HT) on bovine coronary artery in the control Krebs solution (1a, 2a, 3a) and in Krebs containing verapamil (1 $\mu \mathrm{M})(1 \mathrm{~b}, 2 \mathrm{~b}, 3 \mathrm{~b})$. Note that verapamil increased the relaxant effect of noradrenaline and shifted the control curve (1a) to the left (1b), whereas it decreased the ACh and 5-HT responses and shifted their control curves to the right. For more details see text.

artery. Atropine $(1 \mu \mathrm{M})$ reduced the ACh-induced contraction by about $50 \%$. The contraction produced by 5-HT was reduced by both ketanserin $(1 \mu \mathrm{M})$ and methysergide $(1 \mu \mathrm{M})$, by about 95 and $75 \%$ respectively. In the bovine coronary artery, NA produced relaxation of the artery, and this was reduced by about $60 \%$, of the control value, in the presence of propranolol $(1 \mu \mathrm{M})$. Yohimbine $(1 \mu \mathrm{M})$ and prazosin $(1 \mu \mathrm{M})$ did not have significant effect on the NA-induced relaxation in the bovine coronary artery.

Verapamil $(1 \mu \mathrm{M})$ enhanced the NA-induced relaxation, by $38 \pm 2 \%$, whereas it reduced the ACh and 5-HT-induced contractions by $45 \pm 3$ and $40 \pm 1 \%$, respectively.

Figure 1 shows log. concentration-response curves for NA, ACh, and 5-HTinduced responses in the presence and absence of verapamil $(1 \mu \mathrm{M})$, in bovine coronary artery in vitro. Verapamil enhanced the NA-induced relaxation and shifted its control curve to the left (la to $1 \mathrm{~b}$ ), whereas it decreased the ACh and 5HT-induced responses (contractions) and shifted their curves to the right ( $2 a$ to $2 b$ and $3 \mathrm{a}$ to $3 \mathrm{~b}$ ). The mean $\mathrm{EC}_{50}$ values of neurotransmitters in the presence and absence of verapamil $(1 \mu \mathrm{M})$ are shown in Table 1 . Verapamil, diltiazem, and nifedipine relaxed the bovine coronary artery in a concentration-dependent manner. The mechanism of relaxation is not clear from the present experiments but it may be due to inhibition of influx of calcium through voltage-dependent slow "calcium" channels.

In the bovine coronary artery, verapamil was more potent than diltiazem and 
nifedipine (Table 1), in relaxing the artery, suggesting that there may be some degree of tissue selectivity in the action of calcium antagonists. Information on the subgroups of calcium antagonists has been reported recently (SPEDDING, 1985; DEFEUDIS, 1985). Structure-activity and binding studies have revealed 4 different binding sites and 3 different functional classes of calcium antagonists (SPEDDING, 1985). Group 1 contained the dihydropyridine, nifedipine; group II included both verapamil and diltiazem, and group III included the diphenylalkyl amines. Although this classification and those reported by other workers (SINGH and Vaughan-Williams, 1972; Glossmann et al., 1982; Fleckenstein, 1983; MurPhy et al., 1983) may be useful in drug design, such classifications are far from being well-established. Except for the classification of Glossmann et al. (1982), other classifications have assigned verapamil (a phenylalkylamine) and diltiazem (a benzothiazepine) to the same class. On the other hand, DEFEUDIs (1985) has shown that marked differences may exist between verapamil and diltiazem. The present results are in agreement with the above finding, in that verapamil was 5 times more potent than diltiazem and 7 times as potent as nifedipine, in producing relaxation of the bovine coronary artery in vitro.

The interaction of verapamil, diltiazem, and nifedipine with neurotransmitters, $\mathrm{ACh}, \mathrm{NA}$, and 5-HT, was exploited to further investigate the possible differences (in potencies) of the action of calcium antagonists. In the present experiments, both $\mathrm{ACh}$ and 5-HT contracted the bovine coronary artery, whereas NA relaxed the artery. This finding is in keeping with those previously reported by other workers (Chand and Eyre, 1979; Garland and Keatinge, 1982). In the bovine coronary artery, ACh produced large contractions, whereas NA produced small relaxations (Table 1), and this finding was interpreted on the observation, histologically, by other workers (GARLAND and KEATINGE, 1982) that the coronary artery is extensively innervated by cholinergic neurones (KALSNER, 1979). In contrast, the carotid artery of sheep (GrAHAM and KEATINGE, 1975) is contracted by NA, suggesting that species and tissue differences in the action of NA may exist (LONG and STONE, 1985). It has been shown, in rabbit aorta, that the contraction produced by NA was due to the release of internal $\mathrm{Ca}^{2+}$ ions (KARAKI et al., 1979; VAN BREEMEN and SEIGEL, 1980), and/or the influx of calcium through receptor-mediated calcium channels (MeISHERI et al., 1981). The receptor-mediated response was insensitive to calcium antagonists and/or to membrane depolarization (BoLTON, 1979; MEISHERI et al., 1981). In the present experiments, verapamil reduced the ACh and 5-HT-induced contractions whereas it enhanced that produced by NA in bovine coronary artery (Table 1). Thus there may be some selectivity in the action of calcium antagonists (see DeFeudis, 1985). Verapamil, not diltiazem, behaved as a competitive antagonist at 5- $\mathrm{HT}_{2}$ receptors of rabbit aorta (TAYLOR and DEFEUDIS, 1984) and inhibited the 5-HT induced shape change in human platelets (AFFOLTER et al., 1985). Diltiazem was 16 times less potent than verapamil, in displacing the labelled spiperone bound to $\mathrm{D}_{2}$-receptors in striatal homogenates of rat brain (DeVRIES and BeART, 1984). 
In summary, verapamil, diltiazem and nifedipine relaxed the bovine coronary artery, verapamil being a more effective vasodilator than diltiazem and nifedipine. Verapamil reduced the contractions produced by $\mathrm{ACh}$ and 5-HT, whereas it enhanced the relaxation produced by NA in the same artery. The differences in the potency of calcium entry blockers and in their interactions with neurotransmitters used in this study may provide some support for the proposed classification of calcium antagonists suggested by DEFEUDIs (1985).

We wish to thank Mr. E. Carter for technical help and Professor W. R. Keatinge for some discussions.

\section{REFERENCES}

Affolter, H., Burkard, W. P., and Pletscher, A. (1985) Verapamil, an antagonist at 5hydroxytryptamine receptors of human blood platelets. Eur. J. Pharmacol., 108: 157162.

Bolton, T. B. (1979) Mechanism of action of transmitters and other sunstances on smooth muscle. Physiol. Rev., 59: 606-718.

Campbell, J. K., Marshall, R. J., and Winslow, E. (1983) Comparative effects of bepridil and verapamil on isolated coronary and systematic vascular and cardiac muscle. Eur. $J$. Pharmacol., 86: 217-228.

Chand, N. and Eyre. P. (1979) Coronary anaphylaxis in vitro. Br. J. Pharmacol., 67: 193198.

DeFeudis, F. V. (1985) Calcium antagonist subgroups. Trends Pharmacol. Sci., 6: 237-239.

DeVries, D. J. and BeART, P. M. (1984) Competitive inhibition of ${ }^{3} \mathrm{H}$-Spiperone binding to D-2 dopmaine receptors in striatal homogenates by organic calcium channel antagonists and polyvalent cations. Eur. J. Pharmacol., 106: 133-139.

DOCHERTY, J. R. and HYLAND, L. (1985) Evidence for neuro-effector transmission through postjunctional $@_{-2}$ adrenoreceptors in human saphenous vein. Br. J. Pharmacol., 84: 573-576.

Fleckenstein, A. (1983) History of calcium antagonists. Circ. Res., 52, (Suppl. 1): 3-16.

FURCHGOTT, R. F. (1981) The requirement for endothelial cells in the relaxation of arteries by acetylcholine and some other vasodilators. Trends Pharmacol. Sci., 2: 173-176.

Garland, C. J. and Keatinge, W. R. (1982) Constrictor actions of acetylcholine, 5hydroxytryptamine and histamine on bovine coronary artery inner and outer muscle. $J$. Physiol. (Lond.), 327: 363-376.

Glossmann, H., Ferry, D. R., Lubbecke, F., Mewes, R., and Hoffmann, F. (1982) Calcium channels: Direct identification with radioligand binding studies. Trends Pharmacol. Sci., 3: 431-437.

Graham, J. M. and Keatinge, W. R. (1975) Responses of inner and outer muscle of the sheep carotid artery to injury. J. Physiol. (Lond.), 247: 473-482.

KALSNER, S. (1979) The effects of periarterial nerve activation on coronary vessels tone in an isolated and perfused slab of beef ventricle. Can. J. Physiol. Pharmacol., 57: 291-297.

Karaki, H., Kubota, H., and Urakawa, N. (1979) Mobilization of stored calcium for phasic contractions induced by norepinephrine in rat aorta. Eur. J. Pharmacol., 56: 237245.

Long, C. J. and Stone, T. W. (1985) The release of endothelium-derived relaxant factor is 
calcium-dependent. Blood Vessels, 22: 205-208.

Meisheri, K. D., Hwang, D., and van Breemen, C. (1981) Evidence for two separate $\mathrm{Ca}^{2+}$ pathways in smooth muscle plasmalemma. J. Membr. Biol., 59: 19-25.

Murphy, K. M., Gould, R. J., Largent, B. L., and Snyder, S. H. (1983) A unitary mechanism of calcium antagonist drug action. Proc. Natl. Acad. Sci. U.S.A., 80: 860864.

Singh, B. N. and Vaughan-Williams, E. M. (1972) A fourth class of antidysrhythmic action? Effect of verapamil on ouabain toxicity, on atrial and ventricular intracellular potentials, and on other features of cardiac function. Cardiovasc. Res. 6: 109-119.

Spedding, M. (1985) Calcium antagonist subgroups. Trends Pharmacol. Sci., 6: 109-114.

TAYLOR, J. E. and DeFeudis, F. V. (1984) Inhibition of ${ }^{3} \mathrm{H}-$ Spiperone binding to 5-HT receptors of rat cerebral cortex by the calcium antagonists verapamil and D 600. Eur. J. Pharmacol., 106: 215-216.

van Breemen, C. and Seigel, B. (1980) The mechanism of $@$-adrenergic activation of dog coronary artery. Circ. Res., 46: 426-429.

Williams, J. P., Broadbent, M. P., Pearce, A. C., and Jones, R. M. (1983) Verapamil potentiates the neuromuscular blocking effect of enflurane in vitro. Anesthesiology, 59, A 276. 